\title{
Antimicrobial Activity of Psidium Guajava (Guava) Leaves Extract on Extended-Spectrum Beta-Lactamase-Producing Klebsiella Pneumoniae that Cause Multi-Drug Resistant Urinary Tract Infections
}

\author{
Henry Kwadwo Hackman ${ }^{1 *} \quad$ Lawrence Annison ${ }^{1} \quad$ Reuben Essel Arhin ${ }^{2}$ Bright Kojo Azumah ${ }^{2}$ \\ David Boateng $^{2} \quad$ Blessing Nwosu ${ }^{2} \quad$ Mark Appenteng ${ }^{3}$ \\ 1 Accra Technical University, Faculty of Applied Sciences \\ Department of Medical Laboratory Technology, P. O. Box GP 561, Accra, Ghana \\ 2.Accra Technical University, Faculty of Applied Sciences \\ Department of Science Laboratory Technology, P. O. Box GP 561, Accra, Ghana \\ 3.Centre for Plant Medicine Research (CPMR), Mampong-Akuapim, Ghana
}

\begin{abstract}
Extended-spectrum beta-lactamases (ESBLs) are plasmid-mediated enzymes commonly found in the Enterobacteriaceae that are capable of hydrolysing ß-lactams except carbapenems and cephamycins. ESBLs also confer resistance to several non-ß-lactam antibiotics. ESBL producing isolates are predominantly Klebsiella pneumoniae and Eschericia coli. Klebsiella pneumoniae are one of the most common causes of urinary tract infections such as cystitis and pyelonephritis developed by about 150 million people in every given year. ESBLproducing Klebsiella pneumoniae appear susceptible to cephalosporins in vitro using conventional breakpoints but ineffective in vivo. This has limited treatment options for urinary tract infections caused by extended-spectrum beta-lactamases -producing $K$. pneumoniae. This study determined the in vitro efficacy of Psidium guajava on extended-spectrum beta-lactamases -producing $K$. pneumoniae using agar well diffusion and well microplate dilution method. Serial dilutions of the ethanolic extract of the leaves were prepared and tested against the extended-spectrum beta-lactamases-producing K. pneumoniae. The phytochemical screening was performed to determine the antibacterial compounds. The guava leaves extracts concentrations ranging from $50 \mathrm{mg} / \mathrm{ml}-200$ $\mathrm{mg} / \mathrm{ml}$ showed active diameter zone of inhibition. The ethanolic extract of guava leaves had minimum inhibition concentration and minimum bactericidal concentration of $6.25 \mathrm{mg} / \mathrm{ml}$ indicating significant antibiotic activity against the ESBL isolates. The phytochemical screening of the guava leaves showed the presence of antimicrobial phytochemicals such as flavonoids. Ethanolic extracts of guava leaves is proving to be efficacious against multidrug resistant ESBL-producing $K$. pneumoniae, which a major cause urinary tract infections. This offers hope for the development of effective antibiotics against multi-drug resistant urinary tract infections due to the presence of flavonoids in the guava leaf extracts. Therefore, there is the need to determine the toxicological effect of the active antimicrobial compounds isolated in the leaf extracts of guava plant.
\end{abstract}

Keywords: Psidium guajava, Flavonoids, Multi-drug resistant, Extended-spectrum beta-lactamase, Klebsiella pneumoniae

DOI: $10.7176 / \mathrm{JNSR} / 11-22-02$

Publication date: November $30^{\text {th }} 2020$

\subsection{Introduction}

Extended-spectrum beta-lactamases (ESBLs) are plasmid-mediated beta lactamases that are capable of hydrolysing beta-lactams except carbapenems and cephamycins. They are inhibited by beta-lactamase inhibitors such as clavulanic acid, sulbactam and tazobactam. They have been found in the Enterobacteriaceae and other Gram negative bacilli. ESBL producing isolates are predominantly Klebsiella pneumoniae and Escherichia coli (Paterson and Bonomo, 2005).

Klebsiella pneumoniae are inhabitants of the intestinal flora and are among the most common causes of urinary tract infections such as cystitis (bladder infection) and pyelonephritis (kidney infection). It is estimated that about 150 million people develop urinary tract infection in every given year (Flores-Mireles et al., 2015) and are more common in women than men (Salvatore et al., 2011). Enterobacteriaceae are the source of community and hospital acquired infections. Because ESBL enzymes are plasmid mediated, the genes encoding these enzymes are easily transferable among different bacteria. Most of these plasmids not only contain DNA encoding ESBL but also carry genes conferring resistance to several non-beta-lactam antibiotics (Nordmann et al., 2011). Consequently, most ESBL isolates are not only resistant to penicillins, cephalosporins and monobactams but also to other classes of antibiotics including aminoglycosides, fluoroquinolones, tetracyclines, nitrofurantoin and sulfamethoxazole-trimethoprim.

Since 2000, spread of community acquired enterobacterial isolates (Klebsiella pneumoniae) that produce extended-spectrum $\beta$-lactamases (ESBLs) capable of hydrolyzing almost all cephalosporins except carbapenems 
has been reported worldwide (Pitout and Laupland, 2008). Previous studies by Hackman et al. (2013) in Accra established that extended-spectrum beta-lactamase (ESBL) producers were increasingly becoming a public health nuisance due to community acquired and nosocomial infections.

Treatment of these multiple drug-resistant organisms has proven to be a therapeutic challenge. ESBLproducing isolates pose serious public health, financial and logistics challenges because of the limited choice of antibiotics for the treatment of infections by ESBL producing isolates. The screening of natural products has been the source of innumerable therapeutic agents. Higher plants, as a source for new potential drugs is still largely unexplored and only a small percentage of them has been subjected to phytochemical investigation and the fractions submitted to pharmacological screening is very low (Saraswathy et al., 2011).

Guava is mostly cultivated for its fruit and medicinal purposes in the tropical countries. The plant is used for the treatment of diarrhea, dysentery, gastroenteritis, hypertension, diabetes, caries and pain relief and for improvement in locomotors coordination (Naseer et al., 2018). It contains antioxidants, polyphenols, antiviral compounds, anti-inflammatory compounds. Guava leaves also contain many compounds, which act as antimicrobial agents (Naseer et al., 2018).

In this study, the antibacterial activity of ethanolic extract of Psidium guajava leaves was tested against ESBL-producing K. pneumoniae. Phytochemical screening of the plants extract was performed to determine the various compounds. The study was based on the hypothesis that Psidium guajava will possess phytochemical compounds that will have antimicrobial properties against ESBL-bacterial infections through in vitro analysis.

\subsection{Methods}

\subsection{Study Site}

This research work was carried out at the Centre for Plant Medicine Research, Mampong-Akuapim in the Eastern Region of Ghana.

\subsection{Sampling of Test Plant Material and Extracts Preparation}

Thousand gram $(1000 \mathrm{~g})$ of the plant leaves were collected and authenticated at the herbarium at the Centre for Scientific Plant Medicine Research (CPMR), Mampong-Akuapim. The sampling was based on the assumption that the plant is healthy and uninfected. The plant parts were cut into pieces, air dried at $26 \pm 2{ }^{\circ} \mathrm{C}$ for ten days and milled into coarse powder with the aid of an electric blender.

\subsection{Ethanolic Extraction, Evaporation and Freeze Drying of Extracts}

Three hundred grams $(300 \mathrm{~g})$ of the powdered plant part was soaked in $2 \mathrm{~L}$ of $96 \%$ absolute ethanol for 72 hours with occasional stirring and was filtered through Wathman's No.1 filter paper. The filtrate was concentrated with the aid of a rotary evaporator and was freeze-dried using the freeze drying machine at a temperature and reduced pressure of $35^{\circ} \mathrm{C}$ and $100-80 \mathrm{hPa}$ respectively. The dried extract was stored under refrigeration condition $\left(4^{\circ} \mathrm{C}\right)$ until needed.

\subsection{Reconstitution of Serial Concentrations of the Crude Extract}

Eight hundred milligrams $(800 \mathrm{mg}$ ) of the dried crude extracts were disolved in $4 \mathrm{ml}$ of $5 \% \mathrm{v} / \mathrm{v}$ dimethyl sulphoxide (DMSO) to prepare $200 \mathrm{mg} / \mathrm{ml}$ concentration of the leaves extract. Subsequent concentrations of 100, 50, 25, and $12.5 \mathrm{mg} / \mathrm{ml}$ were achieved using the conventional two folds dilution technique.

\subsection{Preparation of Muellar Hinton Agar (MHA) as a Culture Media}

The culture media were prepared according to the manufacturers instruction. Thirty eight grams $(38 \mathrm{~g})$ of the powder was suspended in $1000 \mathrm{ml}$ of demineralized water and heated to boil with agitation to completely dissolve the powder. The medium was then sterilized by autoclaving at $121^{\circ} \mathrm{C}$ for 15 minutes.

\subsection{Detection of ESBL-producing K. pneumoniae using Combined Disc Synergy Method}

MAST ID ${ }^{\mathrm{TM}}$ ESßL Detection Discs (Mast Group, UK) were used to screen and confirm the ESBL phenotypes. The MAST ID ${ }^{\mathrm{TM}}$ ESßL Detection Disks comprise of cefpodoxime $30 \mu \mathrm{g}$ disks, cefpodoxime $30 \mu \mathrm{g}+$ clavulanic acid $10 \mu \mathrm{g}$ disks; ceftazidime $30 \mu \mathrm{g}$ disks, ceftazidime $30 \mu \mathrm{g}+$ clavulanic acid $10 \mu \mathrm{g}$ disks and cefotaxime $30 \mu \mathrm{g}$ disks, cefotaxime $30 \mu \mathrm{g}+$ clavulanic acid 10 $\mu \mathrm{g}$ disks (Paterson and Bonomo, 2005).

Using a pure culture of the test organism, a suspension in distilled water equivalent in density to a McFarland 0.5 opacity standard was prepared. Using a sterile swab, the suspension was spread uniformly across the surface of Mueller-Hinton agar plate. Using a sterile forceps, one of each MAST ID ${ }^{\mathrm{TM}}$ ESßL Detection Disks was placed onto the inoculated medium ensuring that they were evenly spaced. The plates were incubated aerobically at $35-$ $37^{\circ} \mathrm{C}$ for $18-20$ hours. The diameter of any zones of inhibition that were observed were measured and recorded.

The zone of inhibition for the cefpodoxime, ceftazidime and cefotaxime was compared to that of the cefpodoxime, ceftazidime and cefotaxime plus clavulanic acid combination disks. An increase in zone diameter 
of $=5 \mathrm{~mm}$ in the presence of clavulanic acid from any or all of the sets of MAST ID ${ }^{\mathrm{TM}} \mathrm{ES} ß \mathrm{~L}$ Detection Disks indicates the presence of ESBL in the test organism. isolates.

\subsection{Subculturing of Extended-spectrum Beta-lactamase Producing $K$. pneumoniae}

The test organism was subcultured onto Mueller Hinton agar plate and was incubated for 24 hours to obtain a pure culture and to ascertain the viability of the organism. At least four colonies from the pure culture were transfer into sterile peptone water using an inoculation needle and adjusted to turbidity equivalent to $0.5 \mathrm{McFarland}$ Standard.

\subsection{Antimicrobial Susceptibility Testing Using Agar Well-Diffusion Method}

Antimicrobial activity of the plant extracts was assessed using the agar- well diffusion method. A $3 \mathrm{ml}$ inoculum was prepared in peptone water and adjusted to $0.5 \mathrm{McF}$ arland and uniformly spread on the MHA plate using the glass spreader. Wells $(6 \mathrm{~mm}$ diameter) were created in the plate using cork borer and $20 \mu 1$ of the plant extract concentrations $(200 \mathrm{mg} / \mathrm{ml}-12.5 \mathrm{mg} / \mathrm{ml})$ were pipetted into the wells at their respective concentration. Amikacin $(30 \mu \mathrm{g} / \mathrm{ml})$ and colistin $(10 \mu \mathrm{g} / \mathrm{ml})$ disks were used as positive controls and 5\% v/v DMSO and sterile distilled water (SDW) were used as the negative controls. They were allowed to diffuse at room temperature for 30 minutes and the plates were then incubated at $37^{\circ} \mathrm{C}$ for 24 hours. All experiments were carried out in triplicate.

After incubation, the diameter zone of inhibition (DZI) were measured and expressed in millimeters. DZI < $7 \mathrm{~mm}$ was considered inactive; 7-10 mm partially active; $11-16$ active and $>16$ very active as described by Junior and Zanil (2000).

\subsection{Determination of Minimum Inhibition Concentration (MIC)}

Hundred microlitres $(100 \mu \mathrm{l})$ of ethanol extract of the active plants were added to $100 \mu 1$ of $5 \%$ DMSO in the first well of the 96-well microplate and mixed well with a micropipette; $100 \mu \mathrm{l}$ of this dilution was transferred to the next well in the column. This two-fold serial dilution was continued to obtain dilutions ranging from $10^{1}$ to $10^{10}$ with the aid of a micropipette. The final volume in each well was $100 \mu$ l. Solutions of a reference antibiotic amikacin $(30 \mu \mathrm{g} / \mathrm{ml})$ and colistin $(10 \mu \mathrm{g} / \mathrm{ml})$ were also serially diluted in different columns of the microplate as a positive control. The wells were inoculated with $5 \mu \mathrm{l}$ of microbial suspension of turbidity equivalent to 0.5 McFarland and incubated at $37^{\circ} \mathrm{C}$ for 24 hours. After incubation, $40 \mu 1$ of $0.2 \mathrm{mg} / \mathrm{ml} \mathrm{INT} \mathrm{(p-Iodonitrotetrazolium}$ violet) dissolved in sterile distilled water was added to each of the wells. The microplates were examined after additional 30 to 120 minutes of incubation. Bacterial growth was indicated by a red colour of INT reduced to the formazan. The lowest concentration at which a decreased in the red colour is apparent compared to the next dilution was taken as the MIC value.

\subsection{Determination of Minimum Bactericidal Concentration (MBC)}

The MBC values were deduced from those wells with lowest concentrations at which no growth took place after culture for 24 hours of incubation. A small sample from each of those wells was transferred to fresh nutrient agar plates and was incubated overnight at $37^{\circ} \mathrm{C}$ and plates were examined for the presence or absence of living organisms. Plates with no microbial growth were regarded as the minimum bactericidal concentrations.

\subsection{Phytochemical Screening}

Phytochemical screening methods described by Fong et al. (1977) and Ciulei (1982) were used to screen the various extracts for the presence of saponins, reducing compounds, polyuronides, phenolic compounds, alkaloids, triterpenes, phytosterols, flavonoids and anthracenosides.

\subsection{Results}

3.1 Susceptibility of Extended-spectrum Beta-lactamase Producing $K$. pneumoniae against Ethanolic Extract of Psidium guajava

The ethanolic extract of guava leaves varied zones of inhibition as shown in Table 1:

Table 1: Susceptibility of Extended-spectrum Beta-lactamase-Producing K. pneumoniae to ethanolic extract of Psidium guajava leaves

\begin{tabular}{|c|c|c|c|c|c|c|c|}
\hline Standards & & Diam & inhibitio & (mm) & & & \\
\hline Amikacin & Colistin & SDW/ & 200 & 100 & 50 & 25 & 12.5 \\
\hline$(30 \mu \mathrm{g} / \mathrm{ml})$ & $(10 \mu \mathrm{g} / \mathrm{m})$ & DMSO & $\mathrm{mg} / \mathrm{ml}$ & $\mathrm{mg} / \mathrm{ml}$ & $\mathrm{mg} / \mathrm{m}$ & $\mathrm{mg} / \mathrm{m}$ & $\mathrm{mg} / \mathrm{ml}$ \\
\hline $21.0 \pm 0.5$ & $18.0 \pm 0.5$ & 0.0 & $\begin{array}{l}15.6 \pm \\
1.5\end{array}$ & $\begin{array}{l}14.5 \pm \\
1.0\end{array}$ & $\begin{array}{l}12.8 \pm \\
0.3\end{array}$ & $\begin{array}{l}8.6 \\
1.2\end{array}$ & $7.0 \pm 5.0$ \\
\hline
\end{tabular}


3.2 Minimum Inhibition Concentration (MIC) and Minimum Bactericidal Concentration (MBC)

The minimum inhibition concentration (MIC) and minimum bactericidal concentration (MBC) shown in Table 2 were determined using the 96 well microplate.

Table 2: MIC and MBC of ethanol leaves extracts of Psidium guajava against ESBL-producing K. pneumoniae

\begin{tabular}{lll} 
Plant extract & MIC $(\mathrm{mg} / \mathrm{ml})$ & MBC $(\mathrm{mg} / \mathrm{ml})$ \\
\hline Psidium guajava & 6.25 & 6.25
\end{tabular}

\title{
3.3 Phytochemical Constituents
}

The phytochemical constituents of the herbal plant extract were saponins, phenolic compounds, reducing sugars, polyuronoids and flavonoids as shown in Table 3. Previous work by Arima and Danno (2002) had isolated the antimicrobial compounds in guava and elucidated their chemical structure.

Table 3: Phytochemical constituents of Psidium guajava leaves

\begin{tabular}{ll}
\hline Phytochemical & P. guajava \\
\hline Saponins & + \\
Phenolic compounds & + \\
Reducing sugars & + \\
Polyuronoids & + \\
Alkaloids & - \\
Triterpenes & - \\
Phytosterols & - \\
Flavonoids & + \\
Anthracenosides & -
\end{tabular}

Detected $=(+)$; Not Detected $=(-)$

\subsection{Discussion}

The outcome of this study suggested that ESBL-producing $K$. pneumoniae are sensitive to varied concentration $(50 \mathrm{mg} / \mathrm{ml}-200 \mathrm{mg} / \mathrm{ml})$ of the ethanolic extracts of guava leaves. More so, the ethanolic leaves extracts of guava leaves had MIC and MBC of $6.25 \mathrm{mg} / \mathrm{ml}$. This is an indication that the ethanolic extracts of guava leaves have significant antibacterial activity against multi-drug resistant $K$. pneumoniae. This may be because guava leaves possess rich phytochemicals such as saponins, phenolic compounds, reducing sugars, polyuronoids and flavonoids. Flavonoids have been known to possess the antibacterial effect. According to Arima and Danno (2002), four antibacterial compounds were isolated from leaves of guava and these were two new flavonoid glycosides: morin3-O-alpha-L-lyxopyranoside and morin-3-O-alpha-L-arabopyranoside and guaijavarin and quercetin. The plant extract used in this study may contain these four compounds since they fall under flavonoids and the phytochemical screening of the test plant revealed that it contains flavonoids as shown in Table 1.

The activity of the standards (amikacin and colistin) used in this study as positive control corresponds with the results of Hackman et al. (2017) although amikacin $(30 \mu \mathrm{g} / \mathrm{ml})$ used in this study shows a higher diameter zone of inhibition. According to Junior and Zanil (2000) diameter zone of inhibition of 11-16 is considered active and $>16$ is considered very active. From the results, concentrations of the test plant ranging from $50 \mathrm{mg} / \mathrm{ml}-200$ $\mathrm{mg} / \mathrm{ml}$ showed active diameter zone of inhibition. From Table 2, P. guajava had an MIC of $6.25 \mathrm{mg} / \mathrm{ml}$ with MBC of $6.25 \mathrm{mg} / \mathrm{ml}$ with percentage inhibition index of 13.33. This showed that at those concentrations $P$. guajava is able to inhibit the growth of the ESBL-producing $K$. pneumoniae.

\subsection{Conclusions}

The hypothesis for this study proved positive since the plant under study showed activity against the ESBLproducing $K$. pneumoniae. Ethanolic extracts of guava leaves is proving to be efficacious against multi-drug resistant ESBL-producing $K$. pneumoniae, which a major cause urinary tract infections. Phytochemical screening of the leaves showed that it possesses saponins, phenolic compounds, reducing sugars, polyuronoids and flavonoids. The flavonoids such as morin-3-O-alpha-L-lyxopyranoside, morin-3-O-alpha-L-arabopyranoside, guaijavarin and quercetin are known to be responsible for the antibacterial efficacy of the guava leaves extracts. This offers hope for the development of effective antibiotics for the treatment of multi-drug resistant urinary tract infections. Therefore, there is the need to determine the toxicological effect of the active antimicrobial compounds isolated in the leaf extracts of guava plant.

\author{
Abbreviations \\ CPMR: Centre for Plant Medicine Research \\ DMSO: Dimethyl Sulphoxide \\ DZI: Diameter Zone of Inhibition \\ K. pneumoniae: Klebsiella pneumoniae
}


ESBL: Extended-spectrum beta-lactamase

INT: p-Iodonitrotetrazolium violet

MIC: Minimum Inhibitory Concentration

MBC: Minimum Bactericidal Concentration

MHA: Mueller Hinton Agar

P. guajava: Psidium guajava

SDW: Sterile Distilled Water

\section{Declarations}

Funding

Not Applicable

Competing interests

The authors declare that they have no competing interests.

Ethics Approval and consent to participate

Not applicable

Consent for publication

Not applicable

Availability of data and material

All data generated or analyzed during this study are included in this published article.

Authors' contributions

HKH designed the study. DB, BN, MA carried out the experiments and collected the data.

HKH, BKA and REA interpreted the clinical data. All authors' read and approved the final version of the manuscript.

\section{Acknowledgment}

The authors acknowledge the logistical support by Centre for Plant Medicine Research.

\section{References}

Arima H, Danno G (2002) Isolation of antimicrobial compounds from guava (Psidium guajava L.) and their structural elucidation. Bioscience, Biotechnology and Biochemistry, 66:8.

Ciulei I (1982) Methodology for analysis of vegetable drugs. Practical Manuals on Industrial Utilization of Medicinal and Aromatic plants. Edited by the Ministry of Chemical Industry, Bucharest, 73.

Flores-Mireles AL, Walker JN, Caparon M, Hultgren SJ (2015) Urinary tract infections: epidemiology, mechanisms of infection and treatment options. Nature Reviews. Microbiology, 13 (5): $269-84$. doi: $10.1038 /$ nrmicro3432.

Fong EHS, Tin-Wa M, Farnworth NR, Dobberstein RH (1977). Phytochemical Screening Methods. Department of Pharmacognosy and Pharmacology. College of Pharmacy, University of Illinois, USA. pp. 15-20.

Hackman HK, Osei-Adjei G, Ameko E, Kutsanedzie F, Gordon A, Laryea E, Quaye S, Anison L, Brown CA, Twum-Danso K (2013) Phenotypic Determination and Antimicrobial Resistance Profile of Extended Spectrum Beta-lactamases in Klebsiella pneumoniae and Klebsiella pneumoniae in Accra, Ghana. Journal of Natural Sciences Research, 3(12): 75.

Hackman KH, Arhin ER, Gordon A, Mensah BNS (2017) Emergence of Carbapenem-resistant Enterobacteriaceae among Extended-spectrum Beta-lactamase Producers in Accra, Ghana. Journal of Natural Sciences Research, 7 (1): 4-5.

Junior A, Zanil C (2000) Biological screening of Brazilian medicinal plants. Brazilian Journal of Science, 5.

Naseer S, Hussain S, Naeem N, Pervaiz M, Rahman M (2018) The phytochemistry and medicinal value of Psidium guajava (guava). Clinical Phytoscience, 4(1), 1-8.

Nordmann P, Naas T, Laurent P (2011) Global spread of carbapenemase-producing Enterobacteriaceae. Emerging infectious Diseases, 17(10):1791.

Paterson DL, Bonomo RA (2005) Extended-spectrum ß-lactamases: a clinical update. Clinical Microbiology Reviews 2005, 18(4): 657-686.

Pitout JD, Laupland KB (2008) Extended-spectrum $\beta$-lactamase-producing Enterobacteriaceae: an emerging public-health concern. Lancet Infect Dis., 8(3):159-166.

Salvatore S, Salvatore S, Cattoni E, Siesto G, Serati M, Sorice P, Torella M (2011) Urinary tract infections in women. European Journal of Obstetrics, Gynecology, and Reproductive Biology, 156 (2): 131-6. doi:10.1016/j.ejogrb.2011.01.028.

Saraswathy A, Gunalan G, Krishnamurthy V (2011) Antimicrobial Activity of Medicinal Plant Bauhinia variegate Linn. International Journal of Pharmacy and Biological Sciences, 1:400. 